\title{
Procurando informações na Internet: pesquisa em Medicina Tropical e Infectologia
}

\author{
Sonia Pedrozo Gomes*
}

A comunicação da informação passou por várias revoluções da linguagem: da escrita para imprensa e, recentemente, foi revolucionada pelo computador, pois o surgimento da comunicação eletrônica modificou as relações da informação com seus usuários?

Com o fácil acesso à informação na Internet, a pesquisa tornou-se mais dinâmica. $O$ usuário interage diretamente com a informação, mas de qualquer modo, há a necessidade de um planejamento para que se encontre com mais facilidade as informações que se procura.

O maior problema encontrado pelo usuário na Internet é filtrar e recuperar as informações relevantes, devido ao grande volume gerado a cada dia12.

Os usuários da área médica foram os que mais aderiram ao uso da Internet, incorporando todas as vantagens que ela pode oferecer ${ }^{11}$.

A partir de 1997, a Biblioteca do Instituto de Medicina Tropical de São Paulo começou a divulgar sites que fossem de interesse dos seus usuários e houve uma receptividade muito boa.

Através deste artigo serão indicados alguns sites, dentre os muitos existentes, para que os mesmos possam ser úteis a outros pesquisadores da Saúde.

Acrescenta-se, ainda, que os sites são muito dinâmicos e podem, de um dia para outro, sofrer alteração de localização, mas vale a pena serem conferidos.

\section{Sites para levantamento bibliográfico e localização de documentos}

\section{- Base de Bibliotecas - Biblio:}

http://www.ct.ibict.br:82/ccn/admin/ - é uma base que fornece os dados cadastrais de todas as Bibliotecas nacionais que fazem parte da Rede do Catálogo Coletivo Nacional (CCN).
Fornece as instruções, os comandos e as estratégias de busca para o acesso. Clique na vinheta "Acesso às bases de dados - Telnet", para acessá-la.

\section{- Base de Dados Tropical:}

http://www.bdt.org.br/bdt/portugues/ - é da responsabilidade da Fundação Tropical de Pesquisas e Tecnologia "André Tosello", com o objetivo de disseminar informações biológicas on line.

\section{Base de publicações seriadas - TITCCN:}

http://www.ct.ibict.br:82/ccn/admin/ - esta base localiza os periódicos nas bibliotecas brasileiras, cadastradas pelo Instituto Brasileiro de Informação em Ciência e Tecnologia (IBICT). Há a necessidade de se consultar as instruções do programa, para efetuar a busca via Telnet, mas possui uma plataforma amigável para a busca via WWW/Internet.

\section{- Bases de Dados Brasileiras em Ciência e} Tecnologia:

http://bases.ibict.br/ - formada por vários Bancos de Dados nacionais, cadastrados pelo Instituto Brasileiro de Informação em Ciência e Tecnologia (IBICT). O usuário faz a busca pelo assunto e o sistema relaciona qual a Biblioteca e/ou Instituição que possui aquela informação, através do endereço completo, telefone, fax e e-mail.

\section{Bases de Dados de Teses e Dissertações:}

http://www.ct.ibict.br:81/site/owa/si_consulta nesta base, encontram-se as referências bibliográficas e os resumos de teses e dissertações defendidas por brasileiros no Brasil e no exterior. Essa base é coordenada pelo Instituto Brasileiro de Informação em Ciência e Tecnologia (IBICT). Existem duas formas de acesso: uma, via Telnet - consultar as instruções de uso, e outra, via WWW de fácil acesso.

\footnotetext{
* Bibliotecária-chefe do Instituto de Medicina Tropical de São Paulo, São Paulo, SP.

Endereço para correspondência: Sonia Pedrozo Gomes. Av. Dr. Enéas de Carvalho Aguir 470, 05403-000 São Paulo, SP, Brasil. E-mail:spgomes@spider.usp.br

Recebido para publicação em 8/12/98.
} 


\section{- BIREME - Serviço Online:}

http://www.bireme.br - oferece uma infinidade de serviços, 24 horas por dia e 7 dias por semana, tais como: pesquisa nas bases de dados MEDLINE, LILACS, BBO, AdSAÚDE, PAHO e MEDCARIB, que é gratuíta, e o atendimento a pedidos de fotocópia em que o custo é determinado de acordo com a forma de envio das fotocópias, a categoria do usuário e - número de páginas. Mas, para usufruir desses serviços, é necessário pagar a taxa de cadastramento no sistema.

\section{- DEDALUS:}

http://www.usp.br/sibi - é um Banco de Dados Bibliográficos que reune informações sobre os acervos das 39 Bibliotecas, que compõem - Sistema Integrado de Bibliotecas da USP (SIBi/USP), bem como toda a produção intelectual da Universidade de São Paulo. Esse Banco é formado pelas bases de livros e materiais especiais, seriados, teses/ dissertações e produção do corpo docente. Inclui mecanismo de busca de fácil compreensão3.

\section{- HealthGate:}

http://www.healthgate.com/ - oferece as referências bibliográficas e os resumos de periódicos, que estão indexados nas sete bases para pesquisa: AIDSDRUGS, AIDSLINE, AIDSTRIALS, BIOETHICSLINE, CANCERLIT, HealthSTAR e MEDLINE, indicando as referências bibliográficas de artigos de periódicos.

- Institute for Scientific Information - ISI:

http://www.isinet.com/ - é responsável pela publicação do "Current Contents", "Science Citation Index" e outras Bases de Dados.

\section{- Lista de Periódicos Correntes:}

http://www.ffm.br/pg-apre3a.htm relaciona os periódicos correntes das Bibliotecas do Complexo Hospital das Clínicas da Faculdade de Medicina da Universidade de São Paulo, do Instituto de Infectologia Emílio Ribas e do Instituto de Medicina Tropical de São Paulo. A atualização do site é feita a cada dois anos.

\section{- Ministério da Saúde:}

http://www.saude.gov.br/ - possui um mecanismo de busca através de palavra-chave.

\section{- PubMed:}

http://www.ncbi.nlm.nih.gov/PubMed/ - neste site encontra-se uma das mais importantes bases de dados para levantamento bibliográfico MEDLINE da National Library of Medicine, dos
Estados Unidos. Pode-se pesquisar gratuitamente de 1966 até nossos dias.

\section{Sites diversos em saúde1 45678910}

- Academia de Medicina de São Paulo:

http://www.saudetotal.com.br/academia - divulga as publicações e cursos da Entidade.

\section{- AIDS-Grupo Pela Vidda:}

http://www.pelavidda.org.br - valorização, Integração e Dignidade do Doente de AIDS. Instituição sem fins lucrativos que esclarece dúvidas sobre essa doença.

\section{Associação Brasileira de Indústria de Produtos para Saúde (ABPIS):}

http://www.abips.com - é uma Entidade que reúne os principais fabricantes de produtos para a saúde. Possui recomendações quanto ao uso responsável de medicamentos de venda livre.

\section{- Blackwell Science Online Journal:}

http://www.blackwell-science.com/uk/journals.htm - relaciona os 200 periódicos editados pela Blackwell. Na vinheta "search" pode-se consultar os resumos dos artigos publicados nesses periódicos.

\section{- Catálogo PAHO/OPS:}

http://www.paho.org/ - lista todos os serviços oferecidos a seus clientes.

\section{- CDC Search:}

http://www.cdc.gov/search.htm - pode-se consultar o banco de dados do "Centers for Disease Control and Prevention".

- Coordenação Nacional de DST/AIDS:

http://www.aids.gov.br - site com finalidade informativa, esclarece dúvidas com relação às doenças sexualmente transmissíveis e AIDS.

\section{- Doctor BBS:}

http://www.doctorbbs.com - relaciona médicos brasileiros por especialidades e por Estados, responde dúvidas gratuitamente por e-mail.

\section{EcoCyC:}

http://www.ai.sri.com/ecocyc/ecocyc.html enciclopédia sobre E. coli.

\section{- Escolanet:}

http://www.escolanet.com.br - site voltado à Educação, com links interessantes relacionados a Saúde. Para acessá-los, clique primeiro na vinheta "Esporte e Saúde" e depois em "Saúde".

\section{- Fundação Nacional da Saúde:}

http://www.fns.gov.br/ - é um órgão de Administração Nacional do Sistema Único de 
Saúde (SUS). Na vinheta "Agravos à sáude no Brasil" oferece informação sobre várias doenças e, também, o mapa de distribuição da doença nos Estados brasileiros.

\section{- Fundação SEADE:}

http:// www.seade.gov.br - traz todo o tipo de informação sobre o Estado de São Paulo e municípios paulistas.

- Guia do Paciente:

http://www.uol.com.br/bibliot/paciente - guia informativo sobre mais de 3000 remédios utilizados no Brasil.

\section{. HealthLinks Home Page:}

http://www.hslib.washington.edu/ - links para sites sobre saúde.

\section{- Hospital Virtual Brasileiro:}

http://www.hospvirt.org.br - é uma metáfora arquitetônica de um Hospital real. Criado pela Universidade Estadual de Campinas com a finalidade de troca de informações entre os profissionais e estudantes da área de saúde.

- Instituto Paulista de Doenças Infecciosas e Parasitárias:

http://www2.netpoint.com.br/amato/ - traz informações gerais sobre vacinas e doenças infecciosas.

\section{- Medical Terminology Codes:}

http://www.mcis.duke.edu/standards/termcode/ termcode.html - glossário de termos médicos.

- MedicineNet Home Page:

http://www.medicinenet.com/ - guia gratuito de referência médica.

- Ministério da Saúde:

http://www.saude.gov.br/ - traz informações sobre $o$ andamento dos programas, repasse e aplicação de recursos, legislação vigente, licitações e links para outros órgãos relacionados à Saúde.

- Neurociência:

http://www.neuroguide.com - é um guia de sites sobre neurociência.

- Organização Pan-Americana da Saúde OPAS:

http://www.opas.org.br/ - neste site podem ser encontrados projetos, notícias, eventos, relação dos centros colaboradores da OMS/OPAS no Brasil, softwares para download como: Epi Info6, Epi Map, DOEPI, SSS1 etc.

\section{- Oxford Journals:}

http://www.oup.co.uk/jnls/ - encontram-se relacionados os 150 periódicos publicados por esta editora e, também, o fator de impacto das mesmas.

\section{Programa de Biologia Molecular:}

http://www.epm.br/ge/biomol/BIOMOL.HTM - é um site que aborda a Biologia Molecular, através de um programa educacional multimídia.

\section{- Prossiga:}

http://www.prossiga.cnpq.br/ - é um Programa vinculado à presidência do $C N P q$, que tem por objetivo promover o uso da informação e da comunicação para a pesquisa.

\section{Rede UNESP de Difusão da Ciência e da Tecnologia:}

http://www.ibilce.unesp.br/informações/ibilce/ rede_difusao.html - divulga as linhas de pesquisas

\section{Saúde Brasil:}

http://www.ibase.org.br/ saudebrasil - traz informações das mais diversas, relacionadas à Saúde.

\section{Springer-Verlag Journal:}

http://www.springer.de/server/svjps.html - oferece a lista de todos os periódicos por ela editados.

\section{Who Technical Report Series:}

http://www.who.int/dsa/cat97/ztrs.htm encontram-se listados neste site todos os números e títulos desta série, que foram publicados de 1977 a 1998.

\section{Sites de orientações/normas}

- Associação Brasileira de Normas Técnicas: http://www.abnt.org.br/ - é um órgão responsável pela normalização técnica no Brasil.

- Direito Autoral na Internet:

http://www.benedict.com/index.htm - site que fala sobre o direito autoral na Internet.

\section{- Estação Biblioteca do UOL:}

http://www.uol.com.br/bibliot - oferece bases de dados e obras de referência para consulta.

- Fator de Impacto de Periódicos:

http://www.oup.co.uk/jnls/online - a editora Oxford University Press informa o fator de impacto de todos os periódicos por ela editados.

\section{IBGE:}

http://www.ibge.gov.br - o Instituto Brasileiro de Geografia e Estatística traz, entre outras coisas, informações geográficas, cartográficas e estatísticas sobre o Brasil. 


\section{- Manual das Bases de Dados do IBCT:}

http://www.ibict.br/antares/manuais.htm - neste site encontra-se um guia resumido de todas as bases de dados, disponibilizadas pelo Instituto Brasileiro de Informação em Ciência e Tecnologia (IBICT).

- Normas Técnicas da ABNT:

http://www.target.com.br/ - através deste site pode-se pedir orçamento, fazer pesquisa ou compra de normas técnicas. Apenas clique na vinheta "Informações Tecnológicas" e preencha o cadastro.

- Nossa Língua Portuguesa:

http://www.tvcultura.com.br/resguia/portug/ guia1.htm - dá orientação para o uso correto da língua portuguesa.

\section{Sites gratuitos de periódicos com texto integral para download - alguns em fase de experiência}

- Antimicrobial Agents and Chemotherapy http://www.journals.asm.org/

- Applied and Environmental Microbiology http://www.journals.asm.org/

- Dermatology Online Journal http://matrix.ucdavis.edu/DOJdesk/desk.htm/

- DST/AIDS - Boletins Epidemiológicos http://www.aids.gov.br/boletim.htm

- Emerging Infectious Diseases http://www.cdc.gov/ncidod/EID/

- Hematologia Virtual http://www.miranet.com.br/medicina/livro.htm

. Infection and Immunity http://www.journals.asm.org/

- Journal of Bacteriology http://www.journals.asm.org/

. Journal of Clinical Microbiology http://www.journals.asm.org/
- Journal of Virology

http://www.journals.asm.org/

- Medicina \& Saúde

http://www.miranet.com.br/medicina/

- MEDPRESS - Revista Médica Virtual http://www.medpress.med.br

- Microbiology and Molecular Biology Review http://www.journals.asm.org/

- MMMWR

http://www.cdc.gov/epo/mmwr/mmwr.html

- Molecular and Cellular Biology

http://www.journals.asm.org/

- Revista de Saúde Pública

http://www.fsp.usp.br/ rsp/

- SciELO

http://www.bireme.br/scielo - publicacões eletrônicas patrocinadas pelo acordo entre FAPESP, BIREME e editores científicos.

- Weekly Epidemiological Record http://www.who.int/wer/

. Who Health Report

http://www.who.int/home/reports.html

Sites que descobrem e-mail5 67910

- Four11

http://www.four11.com/

. Internet@address Finder

http://www.iaf.net

- Netscape

http://www.netscape.com

. Switchboard

http://www.switchboard.com/

. WhoWhere

http://www.whowhere.com/

. @Brasil

http://www.ie.ufrj.br/@brasil/welcom4.htm

\section{REFERÊNCIAS BIBLIOGRÁFICAS}

1. Almeida E, Silva S, Martelli CMT, Andrade ALSS. Navegando na Internet: as primeiras milhas para pesquisa em saúde. Revista de Patologia Tropical 26:131-135, 1997.

2. Barretto AA. Mudança estrutural no fluxo do conhecimento: a comunicação eletrônica. Ciência da Informação (Brasília) 27:122-127, 1998.
3. Grupo de Estudos: Usuários da Informação. Equipe do SBI/IQSC. DEDALUS: Banco de Dados Bibliográficos da USP (http://www.usp.br/sibi). Manual do Usuário: versão preliminar. São Paulo, Sistema Integrado de Bibliotecas da Universidade de São Paulo, 1998.

4. Guia da Internet. Folha de São Paulo, Revista Folha, 18 novembro, 1998. 
5. Info Exame. São Paulo, volume 13, jan-dez, 1998.

6. Internet World. Rio de Janeiro, volume 2, jan-dez, 1997.

7. Internet World. Rio de Janeiro, volume 3, jan-jul, 1998.

8. Mafra CL, Paula SO, Ozaki LS, Patarroyo JH. Useful Web sites for researchers studying proteins. Brazilian Journal of Medical and Biological Research 30:283288, 1997.
9. Net. São Paulo, volume 3, jan-dez, 1997.

10. Net. São Paulo, volume 4, jan-jul, 1998.

11. Obst $O$. Use of Internet resources by German medical professionals. Bulletin of the Medical Library Association 86:528-533, 1998.

12. Quintana Y. Intelligent medical information filtering. International. Journal of Medical Informatics 51:197204, 1998. 